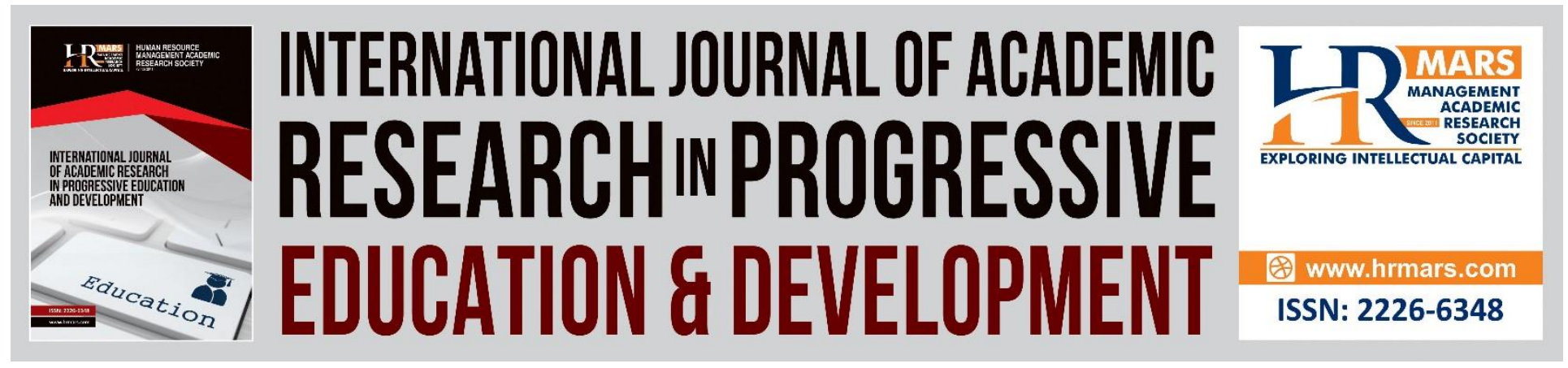

\title{
Strategic Information Management (SIM) In Malaysian Organizations: An Investigation of its Antecedent
}

Norhayati Hussin, Hasnah Hashim and Halida Yu

To Link this Article: http://dx.doi.org/10.6007/IJARPED/v7-i3/4367

DOI: $10.6007 /$ IJARPED/v7-i3/4367

Received: 06 June 2018, Revised: 19 June 2018, Accepted: 23 July 2018

Published Online: 26 July 2018

In-Text Citation: (Hussin, Hashim, \& Yu, 2018)

To Cite this Article: Hussin, N., Hashim, H., \& Yu, H. (2018). Strategic Information Management (SIM) In Malaysian Organizations: An Investigation of its Antecedent. International Journal of Academic Research in Progressive Education and Development, 7(3), 291-304.

Copyright: (C) 2018 The Author(s)

Published by Human Resource Management Academic Research Society (www.hrmars.com)

This article is published under the Creative Commons Attribution (CC BY 4.0) license. Anyone may reproduce, distribute, translate and create derivative works of this article (for both commercial and non-commercial purposes), subject to full attribution to the original publication and authors. The full terms of this license may be seen

at: http://creativecommons.org/licences/by/4.0/legalcode

Vol. 7, No. 3, July 2018, Pg. 291 - 304

http://hrmars.com/index.php/pages/detail/IJARPED

JOURNAL HOMEPAGE

Full Terms \& Conditions of access and use can be found at http://hrmars.com/index.php/pages/detail/publication-ethics 


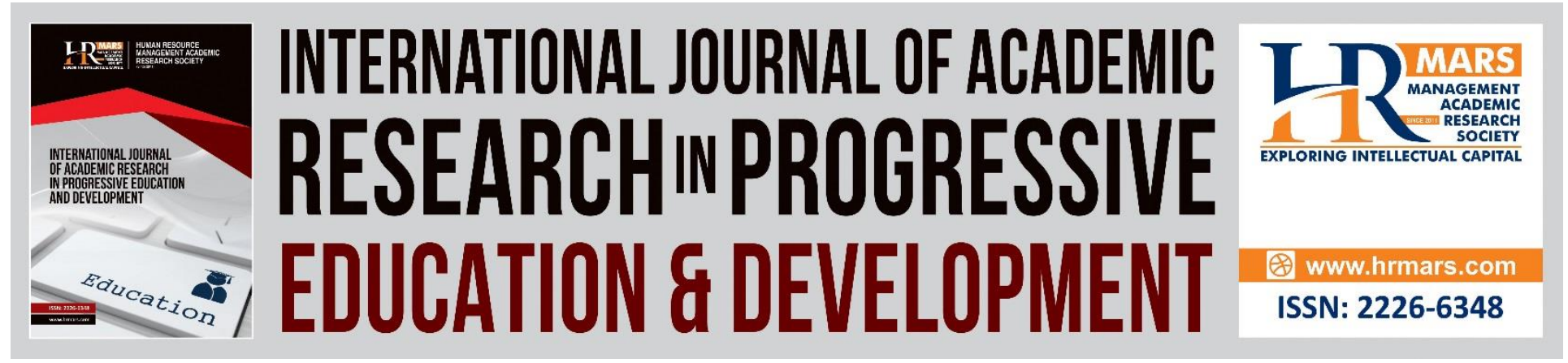

\title{
Strategic Information Management (SIM) In Malaysian Organizations: An Investigation of its Antecedent
}

\author{
Norhayati Hussin, Hasnah Hashim and Halida Yu \\ Faculty of Information Management, Universiti Teknologi MARA, \\ UiTM Selangor, Shah Alam, Malaysia
}

\begin{abstract}
With the advance of Information technology and explosion of information, the business environment is become more competitive than before. Additional technologies such internet, fiber optics, satellite and wireless communication are bringing dramatic and fundamental changes to both business environment and the way they do business. Organization must know how to compete, sustain and achieve strategic position in the industry. In order to do that, they must know how to acquire and utilize information as well as their related resources strategically and they must understand the strategic direction of the organization. Strategic Information Management (SIM) is defined as a situation in which information and related resources (i.e. information technology information professionals) are used or utilized by an organization (profit or non-profit) to support, implement or achieve strategic position in order to gain competitive advantage/strategic advantage. An understanding of the factors that drive SIM to become contributor to organization in winning the marketplace remains an important phenomenon of interest. However, there is a lack of theory-driven empirical research that systematically investigates the factors that influence organizations to be ready or successful implementing SIM in Malaysian organizations. This study bridges the extant gaps in the literature by investigating the antecedent of SIM in Malaysian organization that contributes to the successful implementation of SIM.
\end{abstract}

Keywords: Strategic Information Management, Strategic Information, Sim Antecedents, Business Environment, Library Science

\section{Background to the Study}

Managing information strategically must be a priority for any organization that wants to compete and win in the marketplace (Meagher, 2003; Švárová \& Vrchota, 2014)). In the information age as we live now, the key successful management in organization understands the wealth of information that is available. Information seems a central for strategic planning, management, 
Vol. 7, No. 3, July 2018, E-ISSN: 2226-6348 @ 2018 HRMARS

control, tactical planning and daily operation (Curtis \& Cobham, 2000; Whyte, Stasis, \& Lindkvist, 2016). Managing information strategically is no different than strategically managing finances, human resources, marketing, sales, research and development, operations, communications, or any other element of an organization (Meagher, 2003; Mithas, Ramasubbu, \& Sambamurthy, 2011). It begins with learning how to think strategically and continues with developing a strategic plan, implementing the strategy, and assessing its effectiveness (Webb, 2008). Strategic Information Management (SIM) is a combination between strategic and Information management. It means the management of information to achieve organizational objectives (Myburgh, 2002; Webb, 2008; Williams, Hardy, \& Schubert, 2014). SIM is about strategic uses and applications of information for competitive advantage, and ultimately it is about people. It is strategy that turns an organization's intellectual assets including recorded information, corporate memory and employee expertise into greater productivity, increased competitiveness, and increased collaborative efficiency and effectiveness. (Myburgh, 2002; Webb, 2008; Bharati, Pratyush; Chaudhury, 2014). SIM is used broadly to connote imaginative, systematic management and use of information to achieve objectives that clearly aligned with and contribute to the organization's objectives with the support of Information technology (Dearstyne, 2004; Chaudhury, 2014). Bruening Bruening, Sotto, Abrams and Cate (2008) define SIM as an integrated approach to managing data across the enterprise to minimize risk and enhance competitive opportunity. It recognizes information is a critical strategic business asset, ensure data are protected, minimize risk and facilitates cost-effective legal compliance, systematically assesses the present and future costs and benefits of data to encourage sound policies and investments, resolves conflicting data priorities between the enterprise, supported integrated and strategic decision making. Despite the considerable interest in the concept of SIM in the past two decades, researchers have not yet reached a consensus view on what this term entails. An equally nagging problem is the terminological fog surrounding this concept: terms like 'information systems management', 'information technology management' information system technology management' and 'information system management' are all used casually. Even though such terms do broadly apply to the same concept, each individual name generates very different connotations in terms of where the emphasize in the management process should be directed. In fact the term, SIM is used to cover a very broad range of both technical and managerial activities that have impact on the strategies use of information within the organization.

In the context of this study, Strategic Information Management (SIM) is defined as a situation in which information and related resources (i.e. information technology information professionals) are used or utilized by an organization (profit or non-profit) to support, implement or achieve strategic position in order to gain competitive advantage/strategic advantage.

Based on the discussion above, it shows that SIM can help the organizations to achieve the strategic position in the industry. In today's uncertain economy, especially in light of growing competition across industries, it is becoming more difficult to do so. With the advance of Information technology and explosion of information, the business environment is become more competitive than before. Additional technologies such internet, fiber optics, satellite and wireless communication are bringing dramatic and fundamental changes to both business environment and the way they do business. Organization must know how to compete, sustain 


\section{INTERNATIONAL JOURNAL OF ACADEMIC RESEARCH IN PROGRESSIVE EDUCATION AND}

DEVELOPMENT

Vol. 7, No. 3, July 2018, E-ISSN: 2226-6348 @ 2018 HRMARS

and achieve strategic position in the industry. In order to do that, they must know how to acquire and utilize information as well as their related resources strategically and they must understand the strategic direction of the organization. Accroding to Meagher (2003), organization with SIM can compete and win in the market place. An understanding of the factors that drive SIM to become contributor to organization in winning the marketplace remains an important phenomenon of interest. However, there is a lack of theory-driven empirical research that systematically investigates the factors that influence organizations to be ready or successful implementing SIM in Malaysian organizations. This study bridges the extant gaps in the literature by investigating the antecedent of SIM in Malaysian organization that contributes to the successful implementation of SIM.

The purpose of the study is to examine the antecedent of Strategic information management (SIM) in Malaysian organizations. The antecedent considered important in order for SIM to flourish in any type of organizations. Hence, this study embarks on the following objectives:

a. To investigate the antecedents of SIM in Malaysian organizations

b. To identify the factors that hinders or supports the antecedent of SIM in Malaysian organization.

The findings of this study are expected to benefits all groups who apply and study the Strategic Information Management such as profit or non-profit organizations, researcher, educator as well as practitioners.

\section{Strategic Information Management (SIM): the Significance to the Malaysian Competitive Business Environment.}

According to data from the World Economic Forum's Global Competitiveness Report 2017-2018, Malaysia is now in 23rd place out of 137 countries, up two ranks from 25th place in the previous year's report. (The Star Online, 2017). The report also said that Malaysia was the region's top emerging economy, ahead of countries such as China, which was ranked 27th. Malaysia took second spot among nine Asean countries with Thailand ranked at 32, Indonesia (36), Brunei Darussalam (46), Vietnam (55), Philippines (56), Cambodia (94) and Laos (98). The report however suggests that Malaysia needs to improve in the area of bureaucracy and public service delivery system. In achieving efficiency in delivering services for public, a set of practice must be implemented to manage the system. In fact, for many organizations information is a prerequisite for the production and delivery of their products or services and is critical for the creation of the next generation of product or service. Adoption of SIM in organization is widely accepted to be one of the key mechanisms by which organizational performance and operating efficiency can be improved (Chaffey \& Wood, 2005; Dietel, 2000; EMC Corporation, 2004; Bontis, Richards, \& Serenko, 2011). Moreover, with proper SIM implementation, organization can achieve efficiency in delivering services (GAO, 1994; Caudle, 1996; Marchand and Kettinger, 2001a\&b; Anand and Goyal, 2007; and Webb, 2008; Svärd, 2014). In line with national agenda as mentioned above, clearly for organization in Malaysia to embark and promote the adoption of SIM in companies and to see the antecedent of SIM among them. Thus, it is significant in supporting government objective to deliver excellence services to the public. 
Extensive research had been conducted among researcher in advance and wealth countries on SIM in organization (Marchand, Kettinger, \& Rollins, 2000; Caudle, 1996; Lin and Pervan, 2006; Curly, 2006; Web, 2008; Naranjo-Gil, 2008; Galliers \& Leidner, 2014). Studies on SIM have largely centered on the perceptions and practices of organizations in advanced countries. However, little attempts have been made to empirically investigate its current status of SIM in developing countries such Malaysia. From the previous research of SIM, it can be seen that SIM have improves the way organization conducts their business in the advance world and SIM is important to improve organizational performance. According to Bloom \& Van Reenen (2010) and Powell (2003) to be transforming and to ensure relative improvement require developing countries to do something more different in their development of information practices. Copying from wealth countries will not produce the desired results. As, antecedent of SIM is under environmental uncertainty in Malaysia, with that reason, SIM in Malaysia is important to be studied. Further, it will also provide empirical data to practitioners, researchers and educators for developing professional education and appropriate practices in managing information in organization.

The absence of information about SIM practices that support business activities in Malaysian organizations is a major gap in theoretical and practical literature. Central existence literatures contribute several disciplines like banking sectors, hospitality sector and other profit organizations in advance countries. A search in search engines on February, 2018 shows a stark gap in the number of publications on SIM practices generally and SIM practices in Malaysia. Google.com presented $84,400,000$ hits in general and 415, 000 hits related to SIM practice in the Malaysia environment (0.49\%). Meanwhile, Yahoo.com contained $72,300,000$ strikes in general and 8, 230, 00 hits SIM related to SIM practice in Malaysia (1.1\%). Although a few discussions of Information management (IM) appears in context of Malaysia anyhow, the focus of the research are more on Strategic Planning Information Systems, Information Management and Strategic Information System (Sharul et.al, 2002; ). Meanwhile, in the context of SIM practices the literature mostly from different countries with different approach of study (Huotari, 1995; Caudle 1996, Winter, et.al. 2001; Bhattachariya and Venable, 2006; Hicks, et.al., 2006; Webb, 2008).

\section{Research Methodology}

This section explains how the model indicating antecedent of SIM in Malaysian organizations was developed. Findings from the literature explained in the previous section and input from Information management (IM), Strategic Information management (SIM), Information Strategy and Information Technology literature contributed to the formulation of model. Literature pertinent to the study starts with background of Strategic Information Management (SIM). In order to develop an understanding for SIM, the literature discusses the definition of information management (IM) and strategic information management (SIM); compares and contrasts the differing viewpoints in a prelude to develop a working definition. Following this, from the established definition, the concept of SIM occurred. Once the definition established, the literature discusses previous research done by others. Following this, the contributing factor towards SIM development is identified and characterized within the context of Strategic utilization of information (SUI) and Strategic Utilization of Information systems (SUIS) and then mapped to the development of model to further the study. 
Vol. 7, No. 3, July 2018, E-ISSN: 2226-6348 @ 2018 HRMARS

\section{Findings}

The model consists of antecedent of SIM as dependent variable, organization dimension, information infrastructure and technology infrastructure are as independent variable. Undeniably, there are other potential and possible antecedent factors that could be included into the model but in this study researcher is interested in investigating three specifics dimensions which are illustrated in the figure. These dimensions are chosen because of their strong support from previous studies and their applicability and suitability in the context of strategic information management background in Malaysia.

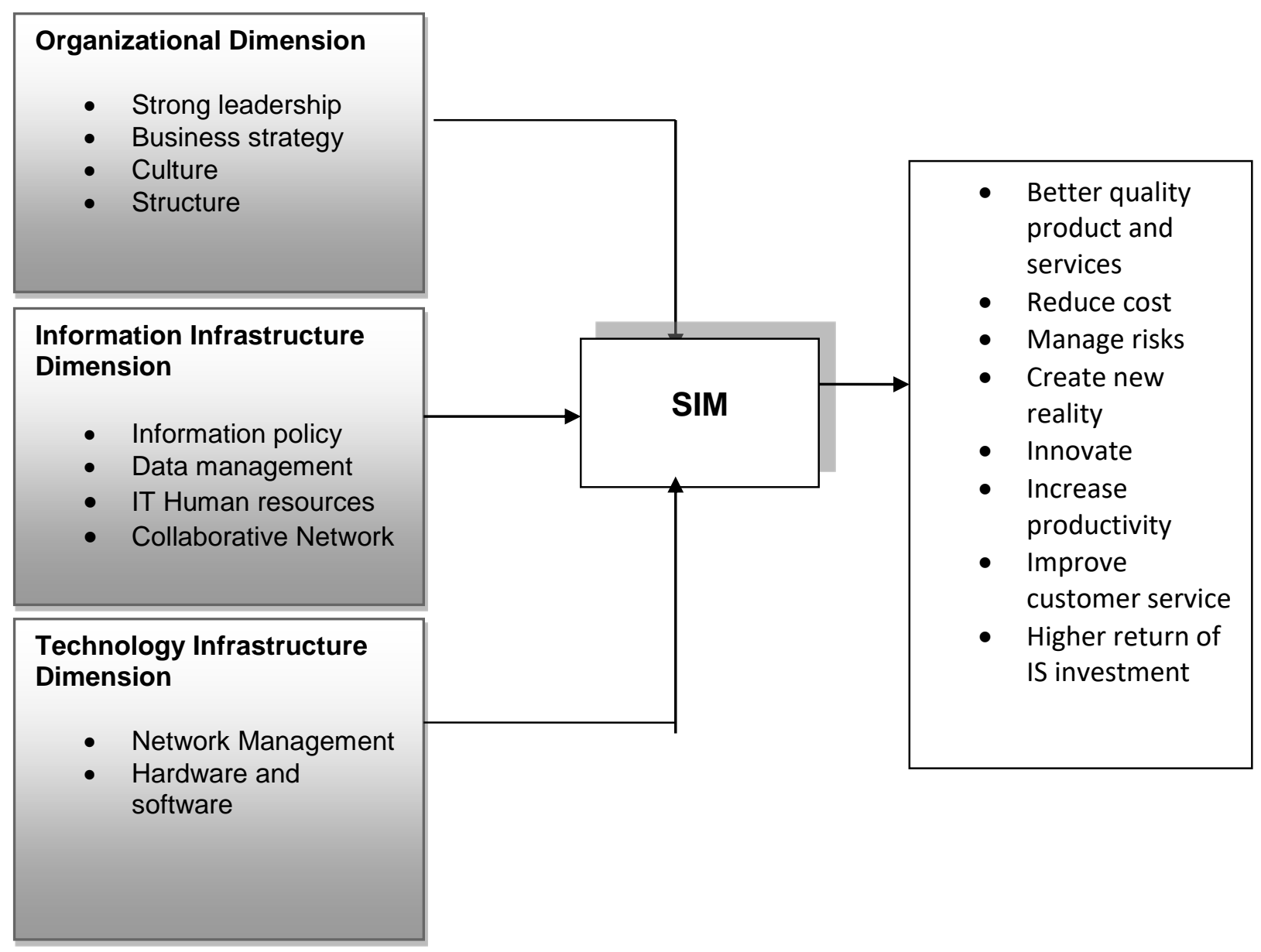

Figure 1: Research Model on Dominants Antecedents of SIM

Based on the research search, this study find out that the most dominant antecedents of SIM which divided into three main dimension, 1) organizational dimension, 2) information infrastructure dimension and 3) technology infrastructure dimension.

\section{Organizational Dimension}

This measure the dimension, this study focuses on four sub-dimension namely, leadership, business strategy, culture and structure. According to Dearstyne, (2004 \& 2005); Detlor, (2010); Smiths.et.al, (1999); Teubner and Mocker, (2009); U.S GAO (1996) the important factor that 
INTERNATIONAL JOURNAL OF ACADEMIC RESEARCH IN PROGRESSIVE EDUCATION AND DEVELOPMENT

Vol. 7, No. 3, July 2018, E-ISSN: 2226-6348 @ 2018 HRMARS

contribute to the success of SIM is a strong leadership of Chief Information Officer $(\mathrm{CIO})$ or related position with the ability to motivate and inspired a group of people to achieve the organization's common goal. Apart of that, the organization should have a very clear business strategy that could navigate them to achieve the strategic position in the industry. Based on Dearstyne, (2004); Hicks, et.al (2006); and Teubner and Mocker (2009); business strategy is the outcome of decisions made to guide an organization with respect to the environment, structure and processes that influence its organizational performance.

The third variable that contributes to the organizational dimension of SIM is culture. Culture form the basis for how individuals operate within the context of organization. It can be defined either by a set of observable behaviors or by the underlying values that drive behavior (Khan, 2005). In SIM, organizational culture is important and manager should not take it lightly (Dearstyne, 2005; Myburgh, 2000). In large organizations, vision statement, mission statements and statements of values are often formalized to describe the company's culture (Kahn, 2005) and Information behavior also is part of organizational culture. It consists of information searching behavior, information use behavior and information seeking behavior (Wilson, 2000). SIM concerns about how people or individual create, acquire, organize, store and distribute and use of information for everyday use (Detlor, 2010). Information behavior will determines how people interact with people whether manual based or computer based systems, whether at the level of human computer interaction or at the intellectual level which will also involve mental acts, such judging the relevance of data or information retrieved.

The fourth variable in this dimension is structure. Today, managers are increasingly regarding information as an important resource. In order to use information assets effectively, organizations should make proper decisions and coordination to prompt improved combinations of information. It should be noted that the organization need to provide a pleasant and supportive organizational structure to facilitate their employee productive execution of the assigned task (Huang and Chen, 2009). Organizing, the process of structuring human and physical resources in order to accomplish organizational objectives, involves dividing tasks into jobs, specifying the appropriate department for each job, determining the optimum number of jobs in each department, and delegating authority within and among departments. One of the most critical challenges facing lodging managers today is the development of a responsive organizational structure that is committed to quality (Teubner and Mocker, 2009; Dearstyne, 2004; Smits, et.al. 1999). Organizational structure determined the information flow in organization and how the firm conducted its businesses. It also shows the process of decision making in the organizations. Appropriate organizational structure depends upon the unique strategy of the business, its unique customer base, its unique sense of products and services and size of the organizational size (Menguc and Auh, 2010). Organizational structure can be viewed from many different perspectives, such as formal/informal (Schminke, et.al., 2002; Merguc and Auh, 2010), centralize/decentralize (Schminke, et.al., 2002), matrix, divisional, functional and horizontally linked structure (Fontaine, 2007). The structure is to facilitate of all units to meet goals and objective of organization and to achieve the goal and objective with a minimum of unplanned and unwanted consequences (Fisher, 2001).

According to Mintzberg (1979), organization with informal structures fosters creativity, risktaking, exploration and experimentation. It also facilitates the flow, exchange and sharing complex and unstructured information and knowledge by supporting cross-functional integration 
INTERNATIONAL JOURNAL OF ACADEMIC RESEARCH IN PROGRESSIVE EDUCATION AND DEVELOPMENT

Vol. 7, No. 3, July 2018, E-ISSN: 2226-6348 @ 2018 HRMARS

and collaboration. Moreover, Informal or decentralization can have major impact on knowledge and information sharing. Informal interactions between units constitute an important means for integrating diffused expert knowledge in organizations and to cross internal and external organizational boundaries (Widen-Wulff and Ginman, 2004; Willem and Buelens, 2009). This informal coordination is based on trust and voluntary cooperation, creating high willingness for cooperation and knowledge and.

Meanwhile, decentralized consisting of teams, mutual adjustment, networking and integration roles allows flexible coordination during task execution and can deal with ad hoc communication and information needs (Willem and Buelens, 2009).

\section{Information Infrastructure}

This domain consists of information policy, data management, IT human resources and collaborative network. This dimension essentially refers to a set of services that support SIM in organization. Those four variables are the important factor to facilitate organization with a better SIM implementation according to Dearstyne (2004); Detlor, (2010); Hicks, et.al., (2006);; Smits, et.al, (1999); Teubner and Mocker, (2009). As mentioned by Dearstyne (2004) for the organization to become strategically manage their information, information policy must be well implemented and information is recognized, discussed and understood to be an important strategic resources. Information policy is a set of strategies and actions to be executed in order to get a result or achieve a goal. An information policy is a policy specifically conceived for and applied to the information field. Pajaro and Betancourt (2007) state that policy establishing mechanisms and generating actions to reduce existing gaps in information access and usage, for both public-domain and private information, by the entire population, with equity, sustainable development, safety and social justice, to foster knowledge. Dearstyne (2004) suggest organization to have written policy statement articulating of information and its strategic usefulness, and the policy must be revisited from time to time and change as needed. As the volume of information produced continues to increase, Information systems are more diversified in their forms and functions, more user-friendly, and also powerful (Megnigbeto, 2010) with the technological rapid changes; possibilities of what people can do with technology became main concern in organization therefore, information policy must be clearly stated to ensure timely information access to any person that is in need and equitable access to information. Moreover, Megnigbeto (2010) stated that information policy aims to make information a resource to be used by everybody; legislation should be developed to determine what public-domain information is accessible to public and what kind of information should be secret.

Knowledge is comes from data and information. Data are raw facts that must be stored, grouped, analyzed and summarized to have meaning. When data are organized and processed in a meaningful context, they become information. Data management is one of important element in SIM (Detlor, 2010). Data management deal with storage and processing, (Detlor, 2010) creating, organizing, sharing and applying data (Eze, Huey Gor, Yaw Ling and Har Lee, 2011). Data management capability includes the capability to manage data. This capability includes database management systems (Kim, 2003), data storing (database or online repository), data tracking, data transaction, data analyzing and data translating. Accenture (2007) has conducted a global survey of 162 Chief Information Officer (CIO) in North America and Europe in wide range 
INTERNATIONAL JOURNAL OF ACADEMIC RESEARCH IN PROGRESSIVE EDUCATION AND DEVELOPMENT

Vol. 7, No. 3, July 2018, E-ISSN: 2226-6348 @ 2018 HRMARS

industries on data management and architecture, found most of the companies believes the importance of data management. Effective data management consists of four building blocks such:

a) Clean, consistent and well understood data achieved by using data quality capabilities.

b) Master data management to organize that data across the enterprise

c) Data governance to ensure the data is effectively utilized

d) Metadata management to understand the critical nature of an organization's data.

Once, an organization has these four building blocks in place, it will be on the path to a successful information management strategy and will enhance its potential to become-high performance business.

Apart from that, one of the important roles of information infrastructure is collaborating capability. It is refers to the ability of linking people so that they can work together. Similar to integrating capability, collaborating capability of information infrastructure can ensure mutual efforts by two or more individual in order to perform task. This capability encourages people to share information and knowledge through collaboration tools. Exchanging and share the information are important activities in organization. By providing collaborative network, organization can decrease transaction costs and allow an exploitation of the economic scale and scope in various activities (Richard, 2000), since they spread the risk and enable access to complementary resources. Moreover, networking can potentially facilitate the avoidance of costs arising from the resolution of conflicts among stakeholders in the long term, as the sharing of ideas among the participants of a network results in a richer understanding and learning of issues, and leads to more innovative activities.

Collaborative Networks are focused on groups accessing and organizing data into actionable formats that enable decision making, collaboration and reuse. Collaborative Networks will increasingly be critically important to business and organizations by helping to establish a culture of innovation and by delivering operational excellence (Fulkerson, 2010). Erkus-Ozturk and Eraydin (2010), conducted a study on collaborative network, found that among tourism companies in Altanya believes the importance of associations in developing collaborative networks and increasing role of local collaboration and networking among the different actors of tourism development. Furthermore, Bleiholder and Naumann (2010) claim that information from different organizational repositories should be integrated in unified view instead in having spread across many sources of organization. Integrated Information Systems provides users and applications with a unified view of heterogeneous data source such fileservers, database, business systems, groupware systems, document repositories, and the web (Benbya and McKelney, 2006). Intranets are private computing networks, internal to organizations, allowing access only to authorized users. They maybe include an internal web along similar lines to the World Wide Web with multiple websites and web pages, electronic mail, newsgroups, online meeting facilities and any number of applications. As the distribution of information is not restricted by time or geographical location can be viewed by any employee within an organization, the intranet provide global communication within the corporate environment internally rather than externally (Curry and Stancich, 2001). Intranets represent a tool of potentially high value to organizations and it is became important strategic element in managing information in organization. 
The fourth important variable in information infrastructure is IT human resource. Success of information systems implementations does not only depend on the quality of hardware and software. It also depends on ability of people to use the information systems for information sharing, ability to conduct the sophisticated algorithm, knowledge on hardware and software to get it all work together (Winter, et.al, 2001). Over the last 20 years, information systems has progressed an academic subject. They help organization to automate many of the main operational processes, improve efficiency and effectiveness. Organizations are experiencing increased demands on their budgets to support hardware and software. Managers need to make judgments and decisions when selecting software and hardware. They need to ensure that hardware and software is selected based on the range of functionality and applications required by organization (ALGA, 2010). For that, they must have knowledge and expertise to select appropriate software and hardware. Xiangfeng et.al (2008) defined IT human resources (human and organizational knowledge, skills, standards, and experience) who are translate IT technological components into a reliable set of understandable, shared IT services that business people can understand. In organization employee must understand and know their responsibility in managing their information systems (Dearstyne, 2004, 2005; Detlor, 2010; Smiths, et.al; Teubner and Mocker, 2009). They must necessarily acquire new competences and qualifications throughout their professional lives so as to successfully meet the needs of their job (Siskos, et.al, 2007). Siskos, et.al (2007) also highlighted, the important skills that should carried out by the IT professional are general skills (project or task management and problem solving) and specialized skills or technical skills (analysis, design, development, testing-maintenance, implement-install and documentation). Meanwhile, they should also have appropriate qualification (formal education) and other with the demands of a profession (formal and informal training).

Apart from that, organization should give incentives and reward to their employee in order to encourage them share information, more innovative, productive in whatever they do (Dearstyne, 2004).

\section{Technology Infrastructure dimension}

With the advent of the information age and the radical change in access to information, the nature of certain types of building systems have changed accordingly. Technology systems in a building encompasses any digital device, digital media, routing devices, operating systems, digital networks and servers, audio-visual systems, cabling systems and digital wireless devices, that are used to provide access to sources of digital information, modify that information, or even create information (Cooper, et.al., 2004).

According to Cooper, et.al, 2004, technology infrastructure is the name typically given to the equipment, the network connections, the control and operating sub-systems, and the cabling of the total technology system as it resides in the building. Network management of large multinational corporations has become so complex that centralized IT infrastructure management solutions are needed. Managing network infrastructure means managing the network devices and the network connections. According to Cisco (2002) network infrastructure have different requirements based on specific variations in topology (mesh or hub-and-spoke), media (frame relay or asynchronous transfer mode (ATM) and overall network (LAN, WAN or MAN). Network managers who design and build networks to support solutions such as voice 
Vol. 7, No. 3, July 2018, E-ISSN: 2226-6348 @ 2018 HRMARS

and video must first consider the components that allow networks to operate properly (Cisco, 2002). Generally, network infrastructure divided into four layers: i) network resilience that provide adaptability, flexibility and distributed response to single points of failure. The dimensions of this network include physical redundancy (links and nodes) and mesh-based network design. ii) communication resilience deploy diverse communications such as telecommunicating, video conferencing and unified messaging that increase and enhance contract with customer, partners and suppliers. iii) Application resilience design elements such as distributed data, center design, data recovery and remote data replication, and iv) business resilience whereby workplace resilience is achieved through the distribution of workers among multiple, dispersed settings. Technologies that enable telecommuting, desk sharing, office hoteling, and employee mobility are essential for ensuring optimal productivity during disruption (Cisco, 2002).

According to research by Forrester (2009), 80\% from 206 global IT decision makers agree that network is a strategic asset for their business. Anyhow, manager face a series of challenge in making sure that network investments keep pace with rising expectations such network traffic is growing quickly (a gigabit network traffic quickly grow to $10 \mathrm{~Gb}$ in less than five years), networks need to be upgraded, need for high- performance networks that minimize latency, decrease packet loss, and prioritize mission-critical traffic and network operations are complex and time consuming. Choosing an appropriate hardware and software for business is a significant part of business operations (Detlor, 2010; Hicks, et.al, 2006; Smits, et.al, 1999). There are some criteria that organization should follow in order to choose the right hardware and software. According to Wendt (2008), there are ten criteria to best select software and hardware in organization as follows:
a) Heterogeneous server and storage support
b) Accounts for differences in performance
c) Manages replication over WAN links
d) Multiple ways to replicate data
e) Application integration
f) Provides multiple recovery points
g) Introduces little or no overhead on the host server
h) Replicates data at different points in the network (host, network or storage system)
i) Centrally managed
j) Scales to manage replication for tens, hundreds or even thousands of servers

Organizations must have their own guidelines to select the best hardware and software that can support their business activities. The guideline is important for the IT department or other respective unit that handle purchasing hardware and software to ensure they have selected according to their budget.

\section{Conclusion and Recommendation}

The exponential growth of information in the new economy focuses attention on the importance of SIM in organization. Many researches have been done related to SIM in advance countries. 
INTERNATIONAL JOURNAL OF ACADEMIC RESEARCH IN PROGRESSIVE EDUCATION AND DEVELOPMENT

Vol. 7, No. 3, July 2018, E-ISSN: 2226-6348 @ 2018 HRMARS

Anyhow, there is absence in preparing model/framework on SIM in the context of Malaysian environment. The proposed model of SIM in the study can be used by the practitioners, researchers or managers to carry out their future research as well as to provide directions for top level management in organization to successfully implement SIM.

\section{References}

Accenture (2007). Cultivating high performance through information management. findings from the Accenture $\mathrm{ClO}$ survey 2007: data management and architecture. Available at: http://www.accenture.com/NR/rdonlyres/352C733D-5DB3-4D56-8A27527EC925ACE4/0/CIO Survey AIMS DMA domain.pdf

Anand,K.S., and Goyal, M. (2007). Strategic information management under leakage in a supply chain.

Bleiholder, J and Naumann, F. (retrieved on August 20, 2010). Conflict handling Strategies in an integrated Information system. DOI: 10.1.1.6.0.9625.pdf

Bhattacharjya, J. and Venable. J, (2006). An Action Research Approach to Strategic Information Systems Planning in a Non-Profit Organisation, in Quality and Impact of Qualitative Research, in Ruth, A. (Ed) Quality and Impact of Qualitative Research. 3rd annual QualIT Conference, Brisbane: Institute for Integrated and Intelligent Systems, Griffith University, pp 29-39.

Available at:

http://www.cit.gu.edu.au/conferences/QuallT2006/proceedings/PDFPapers/Bhattachar jya.pdf

Bruening, P. J , Sotto, L. J, Abrams, M. E and Cate, F. H. (2008). Strategic information management. Privacy and Security Law report, Vol. 07, No. 36, pp:1361- 1363.

Bharati, Pratyush; Chaudhury, A. (2014). SMEs and Competitiveness: The Role of Information Systems. International Journal of E-Business Research, (March), 14-17. http://doi.org/http://dx.doi.org/10.1108/17506200710779521

Bloom, N., \& Van Reenen, J. (2010). Why Do Management Practices Differ across Firms and Countries? Journal of Economic Perspectives, 24(1), 203-224. http://doi.org/10.1257/jep.24.1.203

Bontis, N., Richards, D., \& Serenko, A. (2011). Improving service delivery: Investigating the role of information sharing, job characteristics, and employee satisfaction. The Learning Organization, 18(3), 239-250. http://doi.org/10.1108/09696471111123289

Caudle, Sharon L. (1996). Strategic Resources Management: fundamental practices. Government Information Quarterly, Vol.13, No.1, p:83-97.

Chaffey, D. and Wood, S. (2004). Business information management, improving performance using information systems. Reading, MA: Addison-Wesley.

Cisco (2002). Cisco AVVID Network Infrastructure Enterprise Quality of Service Design Solutions Reference Network Design. Available at: http://citeseerx.ist.psu.edu/viewdoc/download?doi=10.1.1.212.2789\&rep=rep1\&type=

$\underline{\mathrm{pdf}}$

Cooper, R. G., Edgett, S. J., \& Kleinschmidt, E. J. (2004). Benchmarking best NPD practices - I. Research Technology Management, 47(1), 31- 43

Curtis, G., \& Cobham, D (2000). Business information systems: Analysis, design and 
INTERNATIONAL JOURNAL OF ACADEMIC RESEARCH IN PROGRESSIVE EDUCATION AND

DEVELOPMENT

Vol. 7, No. 3, July 2018, E-ISSN: 2226-6348 @ 2018 HRMARS

practice $\left.4^{\text {th }} \mathrm{ed}\right)$. Reading, MA: Addison-Wesley.

Curry, A. and Stancich, L. (2000), "The intranet: an intrinsic component of strategic information management?", International Journal of Information Management, Vol. 20 pp. 249-68.

Dearstyne, B. (2004). Strategic information management: continuing need, continuing opportunities. The Information Management Journal, March/April, p: 28-36. Gale Document Number: A114475664

Dearstyne, B (2006). Information Program leaders in transition. The Information Management journal. Jan/Feb., p: 45-49.

Dearstyne, B.(2007). The FDNY on 9/11: Information and decision making in crisis. Government Information Quarterly, 24, p:29-46. Doi:10.1016/j.giq.2006.03.004

Detlor, B. (2010). Information management. International Journal of Information Management, 30(2), 103-108. http://doi.org/10.1016/j.ijinfomgt.2009.12.001

Dietel, J.E (1998). Improving corporate performance. Information Management Journal.

Erkuş-Öztürk, H., and Eraydın, A. (2010). Environmental governance for sustainable tourism development: Collaborative networks and organisation building in the Antalya tourism region. Tourism Management, Vol. 31 No. 1, pp. 113-124. http://dx.doi.org/10.1016/j.tourman.2009.01.002Eze, U., Huey Goh, M., Yaw Ling, H., \& Har Lee, C. (2011). Intention to Use E-Government Services in Malaysia: Perspective of Individual Users (Vol. 252).

Fulkerson, A. (retrieved on August 21, 2010). The Future of Collaborative networks.

Available at : http://ostatic.com/blog/the-future-of-collaborative-networks

Forrester (2009). The Forrester Wave ${ }^{\mathrm{TM}}$ : Global IT Infrastructure Outsourcing, Q1 2009. Available at: https://www-07.ibm.com/hk/gts/managed services/detail/pdf/forresterwave-global-it-2009.pdf

Galliers, R. D., \& Leidner, D. E. (2014). Strategic information management: challenges and strategies in managing information systems. Information Strategy, 625. Retrieved from http://www.worldcat.org/isbn/0750656190

Hind Benbya, Bill McKelvey, (2006) "Toward a complexity theory of information systems development", Information Technology \& People, Vol. 19 Issue: 1, pp.12-

34, https://doi.org/10.1108/09593840610649952

Kim, W.(2003). "On Three Major Holes in Data Warehousing Today," Journal of Object Technology, vol. 1, no. 4, Sept/Oct., ETH.

Marchand, D. A., Kettinger, W. J., \& Rollins, J. D. (2000). Information Orientation: People, Technology and the Bottom Line. MIT Sloan Management Review, 41(4), 69. Retrieved from http://sloanreview.mit.edu/article/information-orientation-people-technology-andthe-bottom-line/

Mêgnigbêto, E. (2010). Information policy: Content and challenges for an effective knowledge society (Vol. 42).

Mithas, S., Ramasubbu, N., \& Sambamurthy, V. (2011). How Information Management Capability Influences Firm Performance. MIS Quarterly, 35(1), 137-A15. http://doi.org/10.2307/23043496

Pajaro, R. and Betancourt, V. (2007) what is a national information policy: in, Abali, I. Fed. 
INTERNATIONAL JOURNAL OF ACADEMIC RESEARCH IN PROGRESSIVE EDUCATION AND DEVELOPMENT

Vol. 7, No. 3, July 2018, E-ISSN: 2226-6348 @ 2018 HRMARS

Building national information policies: Experiences in Latin America. Kingston: UNESCO, pp. 20-27

Richard, E. T. (2000). The development of aggressive behaviour during childhood: What have we learned in the past century? International Journal of Behavioral Development, 24(2), 129-141. doi:10.1080/016502500383232

Siskos, Y., Grigoroudis, E., Krassadaki, E., \& Matsatsinis, N. (2007). A Multicriteria accreditation system for information technology skills and qualifications. European Journal of Operational Research, 182, 867-885. doi: 10.1016/j.ejor.2006.07.017

Svärd, P. (2014). Information culture in three municipalities and its impact on information management amidst e-government development. IFLA Journal, 40(1), 48-59. http://doi.org/10.1177/0340035214526534

Švárová, M., \& Vrchota, J. (2014). Influence of Competitive Advantage on Formulation Business Strategy. Procedia Economics and Finance, 12, 687-694. http://doi.org/10.1016/S22125671(14)00394-3

Wendt, J.M (2008). 10 criteria to selecting the right enterprise business continuing software. Available at: http://mis-asia.com/technology centre/storage/10-criteria-to-selecting-the-rightenterprise-business-continuity-software (Retrieved on July 30, 2010).

Whyte, J., Stasis, A., \& Lindkvist, C. (2016). Managing change in the delivery of complex projects: Configuration management, asset information and "big data." International Journal of Project Management, 34(2), 339-351. http://doi.org/10.1016/j.ijproman.2015.02.006

Williams, S. P., Hardy, C. A., \& Schubert, P. (2014). Managing enterprise information: meeting performance and conformance objectives in a changing information environment. International Journal of Information Systems and Project Management, 2(4), 5-36. http://doi.org/10.12821/ijispm020401

Winter, A. F., Ammenwerth, E., Bott, O. J., Brigl, B., Buchanuer, A., Graber, S., . . W Winter, A. (2001). Strategic information plans: the basis for systematic information management in hospitals. International Journal of Medical Informatics, 64, 99-109.

Xianfeng, Q., Boxiong, L. and Zhenwei, G. (2008). Conceptual model of IT infrastructure capability and its empirical justification. Tsinghua science and technology. Vol.13, No.3; p:390-394. 